\title{
Telmisartan predominantly suppresses cardiac fibrosis, rather than hypertrophy, in renovascular hypertensive rats
}

\author{
Makoto Kawai, Kenichi Hongo, Kimiaki Komukai, Satoshi Morimoto, Makoto Nagai, Shingo Seki, \\ Ikuo Taniguchi, Seibu Mochizuki and Michihiro Yoshimura
}

Angiotensin II receptor blockers have beneficial effects in patients with cardiac diseases. We examined the effects of an angiotensin II receptor blocker, telmisartan, on cardiac remodeling in renovascular hypertensive rats. Telmisartan was administered to renovascular hypertensive rats at either a high dose ( $5 \mathrm{mg}$ per $\mathrm{kg}$ per day; high-T group) or a low dose ( $0.5 \mathrm{mg}$ per kg per day; low-T group). After 4 weeks, histomorphological studies, including an evaluation of cardiac fibrosis, hypertrophy, vascular changes and measurement of the serum aldosterone concentration, were performed. A significant reduction in systolic blood pressure was obtained in the high-T group, and the heart weight to body weight ratio in the high-T and low-T groups was significantly lower than that in the control renovascular hypertensive group. Cardiac and perivascular fibrosis and the accumulation of collagen were significantly suppressed in the high-T and low-T groups. An increase in the cross-sectional area of the myocytes and vessel hypertrophy were significantly prevented in the high-T group, but not in the low-T group. The dependence of myocyte lengthening on the blood pressure was also prevented in the high-T group, but not to a significant degree. The elevation of the serum aldosterone level observed in the renovascular hypertensive group was prevented in both the high-T and low-T groups.Treatment with telmisartan strongly suppresses the progression of cardiac fibrosis, rather than cardiac hypertrophy, in a manner that is independent of the blood pressure.

Hypertension Research (2009) 32, 604-610; doi:10.1038/hr.2009.61; published online 8 May 2009

Keywords: angiotensin II receptor blocker; cardiac fibrosis; cardiac hypertrophy; peroxisome proliferator-activated receptor gamma; renovascular hypertensive rat

\section{INTRODUCTION}

The renin-angiotensin-aldosterone system is involved in tissue remodeling mechanisms in hypertension and other cardiovascular diseases such as chronic heart failure, ${ }^{1,2}$ left ventricular hypertrophy and myocardial infarction. Angiotensin II type 1 (AT1) receptor blockers (ARBs) are beneficial for the treatment of hypertension and patients with an independent risk for cardiovascular diseases, especially congestive heart failure. ${ }^{3,4}$ Cardiac hypertrophy is strongly related to mortality because of cardiovascular disease during antihypertensive treatment. ${ }^{5}$ As cardiac fibrosis is closely related to the development of cardiac hypertrophy, a drug that could suppress the development of cardiac fibrosis would reduce the cardiovascular risk of patients. Many recent clinical and experimental studies have suggested that aldosterone might induce cardiac hypertrophy through the same pathway as angiotensin II (Ang II). ${ }^{6}$ Consequently, both ARBs and aldosterone blockers should directly inhibit cardiac hypertrophy and fibrosis independent of a reduction in blood pressure. As ARBs mainly inhibit the action of Ang II by inhibiting the AT1 receptor, an increased plasma level of Ang II would stimulate Ang II type 2 (AT2) receptors and exert cardioprotective effects by blocking the AT1 receptor. ${ }^{7}$ On the other hand, both cardiac hypertrophy and fibrosis reportedly occurred after aortic banding in AT1 receptor knockout mice. ${ }^{8}$ Therefore, both cardiac hypertrophy and cardiac fibrosis might be induced through other unknown pathways besides AT1 receptor stimulation. Although there are many ARBs, the differences in the class effects of each ARB are not well understood. The metabolic pathways of telmisartan differ from those of other ARBs. ${ }^{9}$ We investigated the effect of telmisartan on cardiac remodeling in renovascular hypertensive (RHT) rats by measuring physiological parameters and histological alterations to elucidate the distinct progressive mechanism of fibrosis and hypertrophy.

\section{METHODS}

\section{Animals}

This study was conducted in accordance with the guidelines of the Guidance Committee of the Jikei University School of Medicine for the Use and Care of 
Animals. The investigation conformed to the Guideline for the Care and Use of Laboratory Animals published by the US National Institutes of Health (NIH Publication No. 85-23, revised 1996). RHT rats (Goldblatt rats) were surgically prepared from male Wistar rats (body weight: $130-150 \mathrm{~g}$ ) as described elsewhere. ${ }^{10}$ The systolic blood pressure of the operated rats increased to over $140 \mathrm{~mm} \mathrm{Hg}$ after 1 week.

\section{Experimental groups}

Four experimental groups were used: (I) a control group that consisted of normal Wistar rats matched for age (C group, $n=8$ ); (II) a group of RHT rats that did not receive antihypertensive treatment (RHT group, $n=8$ ); (III) a group of RHT rats given a high dose of telmisartan $(5 \mathrm{mg}$ per $\mathrm{kg}$ per day for 4 weeks; high-T group, $n=8$ ) and (IV) a group of RHT rats given a low dose of telmisartan $(0.5 \mathrm{mg}$ per $\mathrm{kg}$ per day for 4 weeks; low-T group, $n=8)$. The drug was administered in the rats' drinking water from weeks 2 to 5 postoperatively. The concentration of telmisartan was adjusted according to the rats' body weights (BWs) and changes in water intake. The amount of drinking water, in which the telmisartan was dissolved, was measured every day. Earlier studies have reported dosages of angiotensin-converting enzyme inhibitors and ARBs capable of decreasing blood pressure by $\sim 15-20 \%$ in hypertensive rats. ${ }^{11,12}$ We used these earlier findings as a guide to set the high and low doses of telmisartan ( 5 and $0.5 \mathrm{mg}$ per $\mathrm{kg}$ per day, respectively) used in this study.

\section{Physiological measurements}

Systolic blood pressure and diastolic blood pressure were measured using the tail-cuff method (BP-98A; Softron, Tokyo) every other week after the operation; the heart rate was also determined at the same time. At the end of treatment, the rats were weighed and their blood was collected under sodium pentobarbital $\left(5 \mathrm{mg} \mathrm{kg}^{-1}\right.$ i.p.)-induced anesthesia. Then, phosphate buffered saline ( $136.8 \mathrm{~mm} \mathrm{NaCl}, 2.7 \mathrm{~mm} \mathrm{KCl}, 8.1 \mathrm{~mm} \mathrm{Na} \mathrm{NPO}_{4}$ and $1.46 \mathrm{~mm} \mathrm{KH}_{2} \mathrm{PO}_{4}$ ) was perfused through the abdominal aorta and the heart was removed and immediately placed in ice-cold phosphate buffered saline. A cross section of the heart was fixed in $10 \%$ formalin for histological analysis.

\section{Histological study}

The fixed cardiac tissues were embedded in paraffin, and sectioned into $4 \mu \mathrm{m}$ thick slices. Myocardial preparations of each group were stained using the following stains: Masson's trichrome stain for the detection of cardiac fibrosis, Sirius red for the detection of collagen and anti-Connexin 43 antibody (Santa Cruz Biotechnology, Santa Cruz, CA, USA) for the detection of myocyte size. To estimate the degree of myocardial fibrosis, photomicrographic figures were digitalized using a Nikon digital image system (Nikon E990, Tokyo, Japan). The total myocardial area and the area of fibrosis in the myocardial tissue were assigned numerical values using $\mathrm{NIH}$ imaging software (National Institute of Health, Bethesda, MD, USA); the area of myocardial fibrosis was then normalized by the cross-sectional area (CSA) of the myocardial tissue of the left ventricle. The cell length and CSA were measured using the method reported by Obayashi et al. ${ }^{11}$ An immunohistochemical study was performed using the anti-Connexin 43 antibody and a streptoavidin-biotin staining kit (Nissui, Tokyo, Japan). In this study, 40-50 myocytes from each rat were randomly selected to determine the cell size.

\section{Morphological study of coronary vascular changes}

Images of the coronary microvessels were also digitalized using NIH imaging software ${ }^{13}$ to assess perivascular fibrosis and vascular wall hypertrophy of the medial smooth muscle, as described earlier. ${ }^{14}$ In each rat, three or four coronary vessels with a luminal diameter of over $70 \mu \mathrm{m}$ were selected. The perivascular fibrosis to luminal area ratio and the medial vascular wall thickness to luminal area ratio were calculated. The morphometric measurements were performed under a magnification of $\times 400$.

\section{Measurement of serum aldosterone concentration}

In each group, the concentration of serum aldosterone was measured using the enzyme antibody method according to the instructions provided by the manufacturer's kit (SRL, Tokyo, Japan).

\section{Statistical analysis}

Statistic analyses were performed using the SPSS 11.5J software package (SPSS Japan Inc., Tokyo, Japan). Values were expressed as the mean \pm s.e.m. Differences among the groups were tested using a one-way analysis of variance (ANOVA) combined with Scheffe's post hoc test. A value of $P<0.05$ was considered statistically significant.

\section{RESULTS}

\section{Physiological parameters}

The systolic blood pressure, diastolic blood pressure, heart rate, BW and heart weight to body weight (HW/BW) ratio for each group are shown in Table 1. The systolic blood pressure and diastolic blood pressure significantly increased in the RHT group but were effectively lowered in the high-T group. However, the blood pressure in the low$\mathrm{T}$ group was similar to that in the RHT group. The heart rate was significantly elevated in the RHT group $(P<0.05)$ compared with in the control, but no significant difference in the heart rate was observed between the two treatment groups. The HW/BW ratio was significantly increased in the RHT group, compared with in the control group, but it was significantly lower in the high-T group $(-22.2 \%)$ and the low-T group $(-11.1 \%)$, compared with the RHT group.

\section{Measurement of myocardial fibrosis area}

Masson's trichrome stain (blue) was used to show fibrosis in the myocardial tissues, as shown in Figures 1a-d. Staining for fibrosis was observed mainly at the periphery of the vessels, and the percentage of cardiac area with fibrosis was clearly higher in the RHT group (Table 2). However, the fibrotic area was significantly lower in the high-T group and the low-T group, compared with in the RHT group (Table 2). This decrease was independent of the blood pressure level.

\section{Perivascular fibrosis and vessel hypertrophy in cardiac tissue} In the RHT group, the fibrotic tissue caused significant hyperplasia, mainly around the vessels. However, perivascular fibrosis was clearly inhibited by telmisartan in both treatment groups (Figures $2 \mathrm{a}-\mathrm{d}$ ). The extent of perivascular fibrosis was calculated by dividing the stained area by the luminal area (Table 2). In the RHT group, the ratio of perivascular fibrosis was significantly larger than that in the control group $(P<0.05)$, whereas the ratio of perivascular fibrosis was significantly smaller in both of the telmisartan treatment groups (Table 2).

The progression of vessel hypertrophy was calculated by dividing the medial wall thickness by the luminal diameter (Figures $2 \mathrm{a}-\mathrm{d}$, Table 2). The ratio of vessel hypertrophy in the RTH group was

Table 1 Effects of telmisartan on physiological parameters after 4 weeks of treatment

\begin{tabular}{lccll}
\hline & Control & RHT & High-T & Low $-T$ \\
\hline SBP (mm Hg) & $127 \pm 2$ & $222 \pm 9^{*}$ & $171 \pm 6^{*}, * *$ & $226 \pm 6^{*, * * *}$ \\
DBP (mm Hg) & $97 \pm 4$ & $164 \pm 9^{*}$ & $141 \pm 5^{*}$ & $165 \pm 5^{*, * * *}$ \\
HR (b.p.m.) & $402 \pm 12$ & $459 \pm 13^{*}$ & $452 \pm 13$ & $443 \pm 11$ \\
BW (g) & $311 \pm 7$ & $236 \pm 15^{*}$ & $275 \pm 7$ & $309 \pm 8^{* *}$ \\
HW (mg) & $902 \pm 20$ & $1070 \pm 41^{*}$ & $951 \pm 28$ & $1213 \pm 27^{*, * *, * * *}$ \\
HW/BW & $2.9 \pm 0.1$ & $4.5 \pm 0.3^{*}$ & $3.5 \pm 0.1^{*, * *}$ & $4.0 \pm 0.2^{*, * *, * * *}$ \\
\hline
\end{tabular}

Abbreviations: SBP, systolic blood pressure; DBP, diastolic blood pressure; HR, heart rate; $\mathrm{BW}$ body weight; HW, heart weight: HW/BW, heart weight to body weight ratio; RHT, renovascular hypertensive rats without treatment; high-T. RHT rat treated with a high dose of telmisartan $(5 \mathrm{mg}$ per kg per day for 4 weeks); low-T, RHT rat treated with a low dose of telmisartan $(0.5 \mathrm{mg}$ per $\mathrm{kg}$ per day for 4 weeks).

Values are the mean \pm s.e.m. $n=6-8$ for control, RHT, high-T and low-T groups.

Values are the mean \pm s.e.m. $n=6-8$ for control, RHT, high-T and low- $\mathrm{g}$
${ }^{*} P<0.05$ vs. control; ${ }^{* *} P<0.05$ vs. RHT; ${ }^{* * *} P<0.05$ vs. high-T groups. 
a

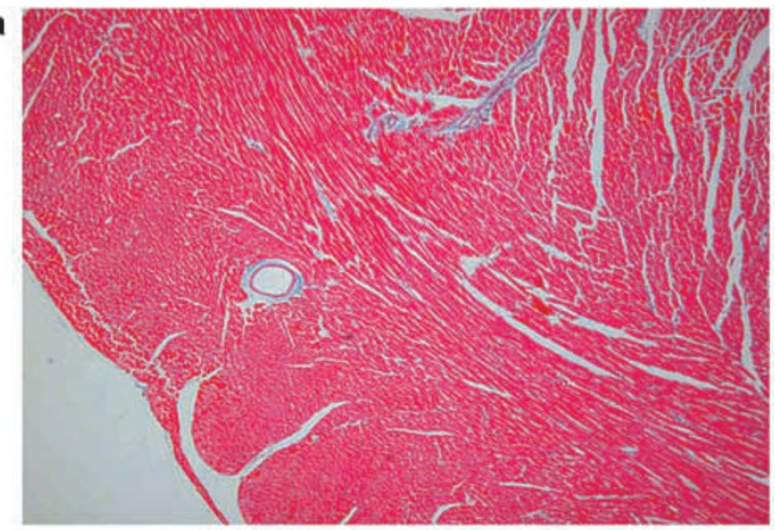

c

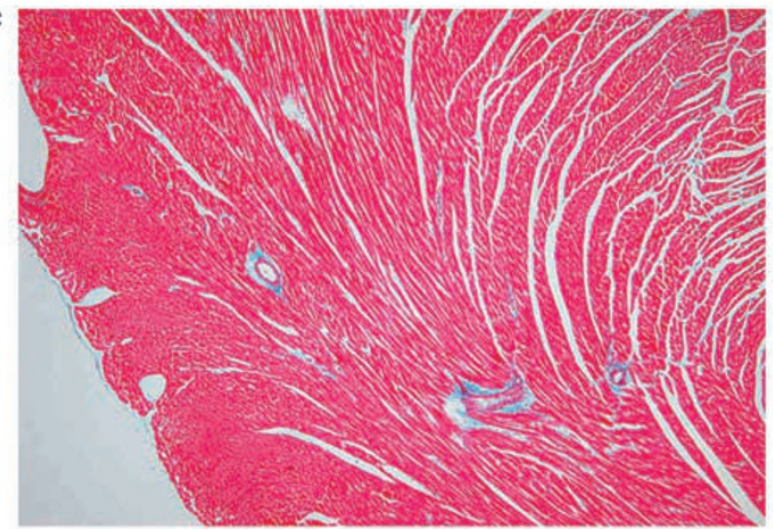

b

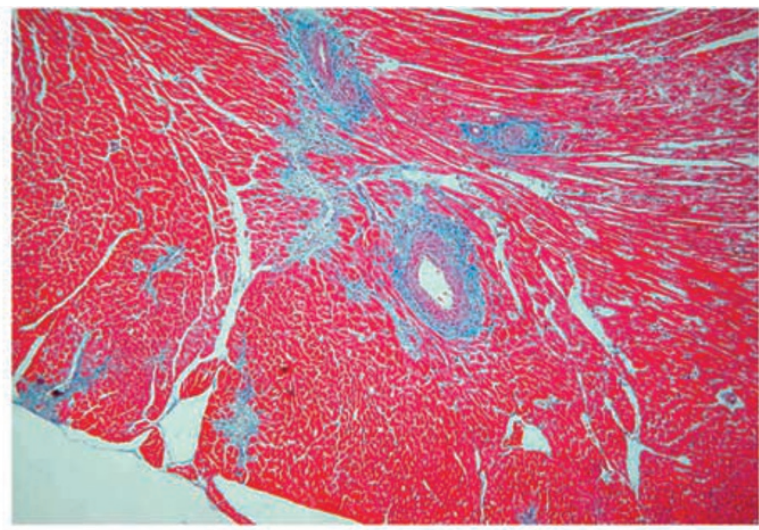

d

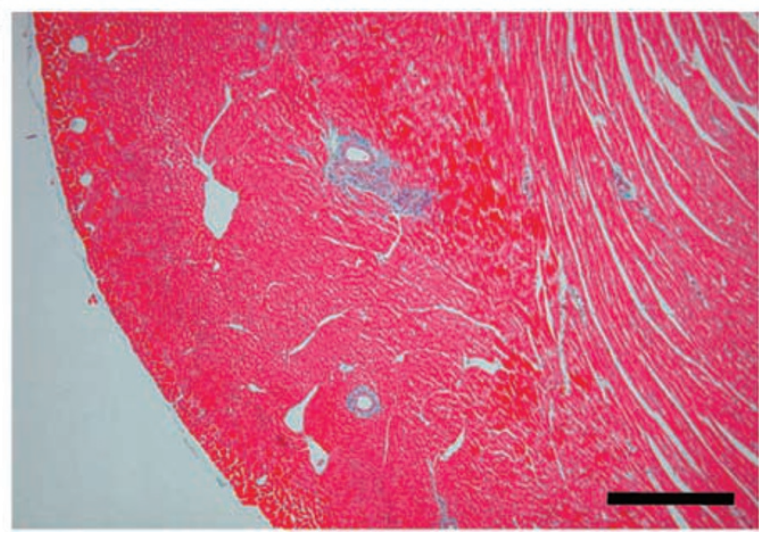

Figure 1 Cardiac fibrosis. Photomicrographs of cardiac sections stained with Masson's trichrome stain in each group. (a) control group, (b) RHT group, (c) high-T group and (d) low-T group. Bar: $500 \mu \mathrm{m}$.

Table 2 Effects of telmisartan on histological results after 4 weeks of treatment

\begin{tabular}{lcccc}
\hline & Control & $R H T$ & High-T \\
\hline Cardiac fibrosis (\%) & $1.17 \pm 0.08$ & $4.46 \pm 0.47^{*}$ & $1.30 \pm 0.06^{* *}$ & $1.80 \pm 0.23^{* *}$ \\
Perivascular fibrosis (ratio) & $0.80 \pm 0.04$ & $2.96 \pm 0.04^{*}$ & $1.26 \pm 0.12^{* *}$ & $1.53 \pm 0.10^{* *}$ \\
Accumulation of collagen (\%) & $0.32 \pm 0.03$ & $3.22 \pm 0.72^{*}$ & $0.40 \pm 0.02^{* *}$ & $0.91 \pm 0.18^{* *}$ \\
Vessel hypertrophy (ratio) & $0.65 \pm 0.04$ & $1.65 \pm 0.17^{*}$ & $1.01 \pm 0.09^{* *}$ & $1.23 \pm 0.06^{*}$ \\
Cell length of myocyte ( $\mu \mathrm{m})$ & $72.6 \pm 1.9$ & $79.1 \pm 1.0^{*}$ & $76.2 \pm 1.0$ & $78.0 \pm 0.9^{*}$ \\
CSA of myocyte $\left(\mu \mathrm{m}^{2}\right.$ ) & $122.8 \pm 7.2$ & $183.2 \pm 4.2^{*}$ & $136.1 \pm 5.5^{* *}$ & $162.2 \pm 7.4^{*, * * *}$ \\
\hline
\end{tabular}

Abbreviations: cardiac fibrosis (\%), ratio of cardiac fibrosis area to cross-sectional area of the heart; perivascular fibrosis (ratio), ratio of perivascular fibrosis to luminal area; vessel hypertrophy (ratio), ratio of medial vascular wall thickness to luminal area; accumulation of collagen (\%), ratio of accumulated collagen fiber area to cross-sectional area of the heart; cell length ( $\mu \mathrm{m}$ ) and CSA $\left(\mu \mathrm{m}^{2}\right)$ of myocyte, $40-50$ myocytes from each group were randomly selected to determine the cell size; RHT, renovascular hypertensive rats without treatment; high-T, RHT rat treated with a high dose of telmisartan ( $5 \mathrm{mg}$ per kg per day for 4 weeks); low-T, RHT rat treated with a low dose of telmisartan ( $0.5 \mathrm{mg}$ per $\mathrm{kg}$ per day for 4 weeks).

Values are the mean \pm s.e.m. $n=6-8$ for control, RHT, high-T and low-T groups.

${ }^{*} P<0.05$ vs. control; ${ }^{* *} P<0.05$ vs. RHT; ${ }^{* * *} P<0.05$ vs. high-T groups.

significantly larger than that in the control group $(P<0.05)$, whereas the ratio of vessel hypertrophy in the high-T group, was significantly smaller than that in the RTH group; the ratio of vessel hypertrophy in the low-T group tended to be smaller than that in the RTH group, but the difference was not significant (Table 2).

\section{Accumulated collagen in the cardiac muscle}

The percentage of the area containing accumulated collagen (interstitial and perivascular) was calculated by dividing the Sirius red stained area by the observed unit CSA of the cardiac muscle tissue; this value was higher in the RHT group than in the control group (Figures $3 \mathrm{a}$ and $\mathrm{b}$, Table 2). However, the accumulation of collagen was strongly inhibited in both treatment groups (Figures $3 \mathrm{c}$ and d, Table 2).

\section{Measurement of myocyte size}

Cardiac muscle tissue was immunostained with anti-Connexin 43 to assess the myocyte size (Table 2). The length of the myocytes and the CSA were significantly higher in the RHT group and low-T group than in the control group. The CSA of the myocytes increased depending on the level of hypertrophy (Table 2). This increase was observed in the low-dose telmisartan group, but not in the high-dose telmisartan group. The length of the myocytes seemed to elongate in a blood pressure-dependent manner. 


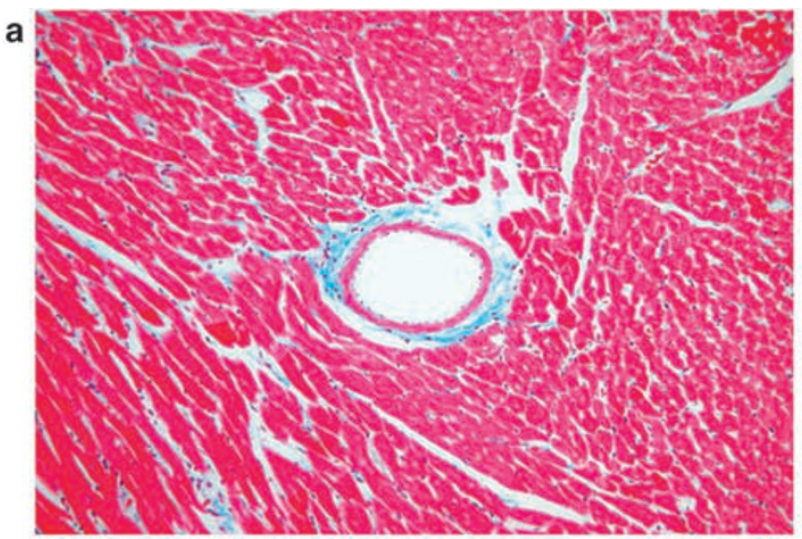

b



c

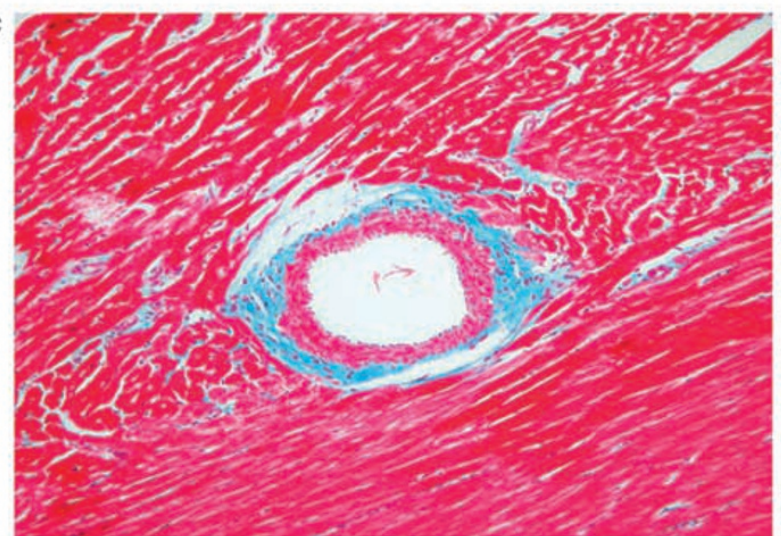

d

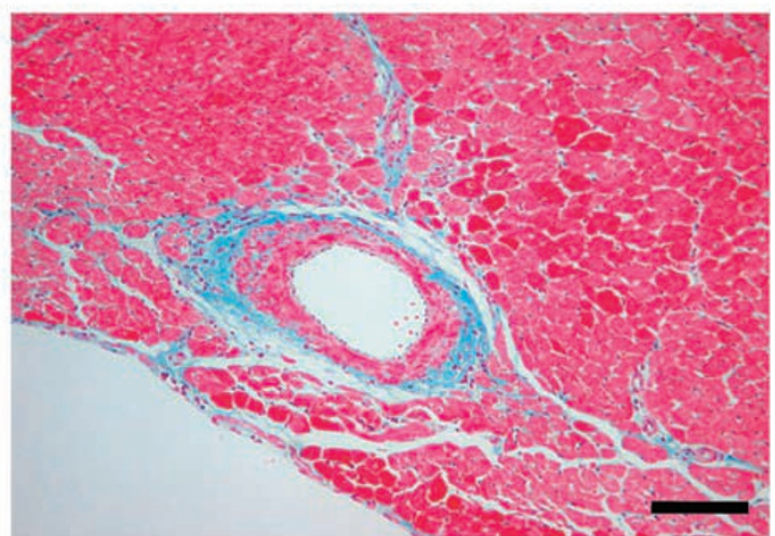

Figure 2 Perivascular fibrosis and vessel hypertrophy. Photomicrographs of vascular sections stained with Masson's trichrome stain in each group. (a) control group, (b) RHT group, (c) high-T group and (d) low-T group. Bar: $100 \mu \mathrm{m}$.

\section{Cardiac fibrosis vs. cardiac hypertrophy after treatment with telmisartan}

The larger cardiac fibrosis area in the RHT group was strongly suppressed by treatment with a low dose of telmisartan (low-T group), independent of the blood pressure level (Figure 4a, high-T group: $1.30 \pm 0.06 \%$ and low-T group: $1.80 \pm 0.23 \%,-70.9$ and $-59.6 \%$ vs. RHT group: $4.46 \pm 0.47 \% ; P<0.05$, respectively). The CSA of the myocytes, representing the grade of cardiac hypertrophy, was larger in the RHT group (Figure $4 \mathrm{~b}$; RHT: $183.2 \pm 4.2 \mu \mathrm{m}^{2} v$ s. $122.8 \pm 7.2 \mu \mathrm{m}^{2}$ in the control group; $\left.P<0.05\right)$. This increase in the CSA was prevented by treatment with a high dose of telmisartan (high-T group: $136.1 \pm 5.5 \mu \mathrm{m}^{2},-25.7 \%$ vs. RHT group; $P<0.05$ ), but not by treatment with a low dose of telmisartan (low-T group: $\left.162.2 \pm 7.4 \mu \mathrm{m}^{2}\right)$.

\section{Serum aldosterone level in the RHT group}

The serum concentration of aldosterone was significantly increased in the RHT group $\left(663 \pm 102 \mathrm{pg} \mathrm{m}^{-1}\right.$ in the RHT group $v$. $153 \pm 12 \mathrm{pg} \mathrm{ml}^{-1}$ in the control group; $\left.P<0.05\right)$, but not in the telmisartan groups (high-T group: $202 \pm 15 \mathrm{pg} \mathrm{ml}^{-1}$, low- $\mathrm{T}$ group: $182 \pm 32 \mathrm{pg} \mathrm{ml}^{-1}$; NS vs. the control group). These results show that telmisartan might strongly inhibit increases in serum aldosterone by blocking Ang II receptors in both treatment groups.

\section{DISCUSSION}

Anti-hypertensive drugs do not always reduce blood pressure down to a normal level in clinical practice. Consequently, it is important to examine whether treatment with a low dose of ARBs, which may not have the desired anti-hypertensive effect, may nevertheless have beneficial effects regarding cardiac hypertrophy.

Telmisartan significantly reduced systolic blood pressure when administered at a high dose, but not at a low dose; in addition, it prevented cardiac and perivascular fibrosis in RHT rats regardless of its dose level and in a manner that was independent of the extent of blood pressure reduction. Moreover, although some degree of cardiomyocyte and vessel hypertrophy was still observed in the low-dose telmisartan (low-T) group, cardiac interstitial fibrosis was clearly suppressed in this group. Furthermore, this anti-remodeling effect in the RHT rat was strongly inhibited in the high-dose telmisartan (high-T) group. The increase in blood pressure and the progression of cardiac hypertrophy observed in RHT rats result from the activation of the renin-angiotensin (RA) system. ${ }^{15}$ As cardiac fibrosis is accompanied by the proliferation of cardiac fibroblasts and the accumulation of collagen, these changes lead to an increase in myocardial stiffness and cause a breakdown of cardiac function, ${ }^{16}$ eventually resulting in heart failure. Earlier clinical and experimental studies have showed the beneficial effects of RA blockers against cardiac remodeling. However, the dosage of each RA blocker remains controversial; it is not clear whether a low dose of ARB exerts cardioprotective effects independent of the extent of blood pressure reduction. Our results suggested that the suppression of cardiac and perivascular interstitial fibrosis caused by telmisartan was independent of the extent of blood pressure reduction, whereas cardiomyocytic vessel hypertrophy was closely related to high blood pressure. In some earlier reports, telmisartan has been shown to exert anti-fibrotic effects by inhibiting several pathways (for example, gene expression of collagen and TGF- $\beta$, 
a

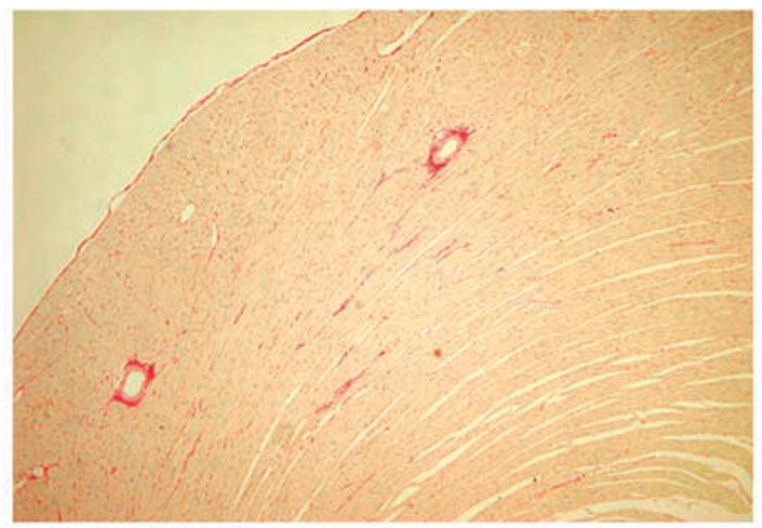

C

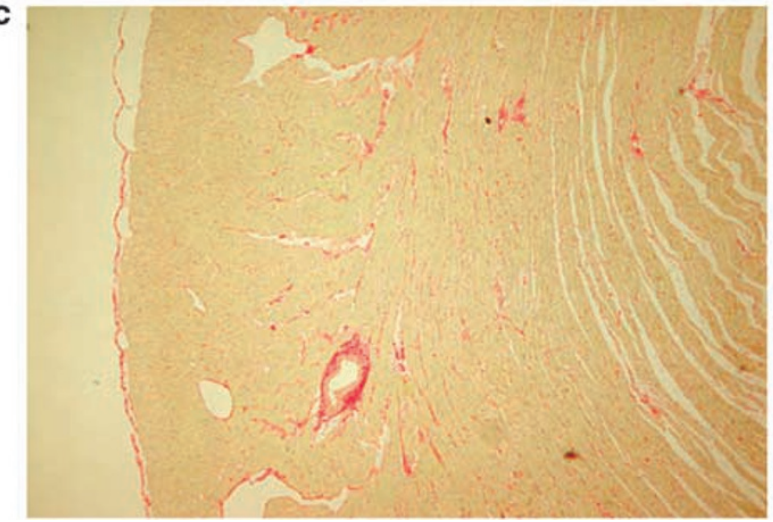

b

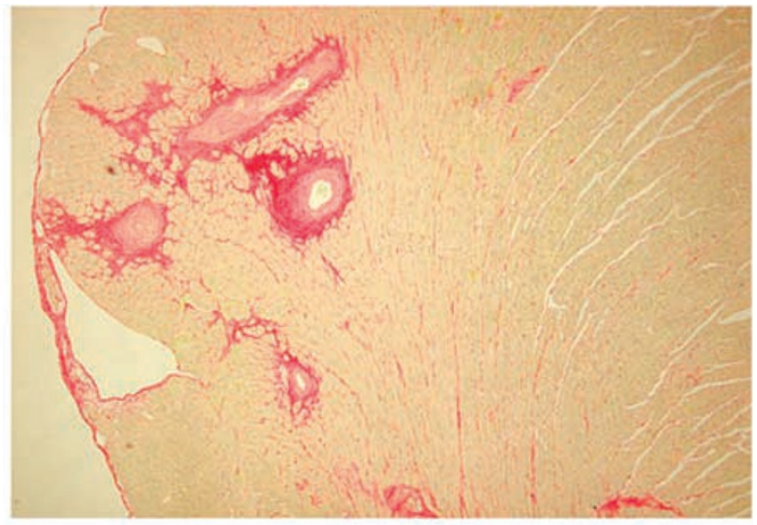

d

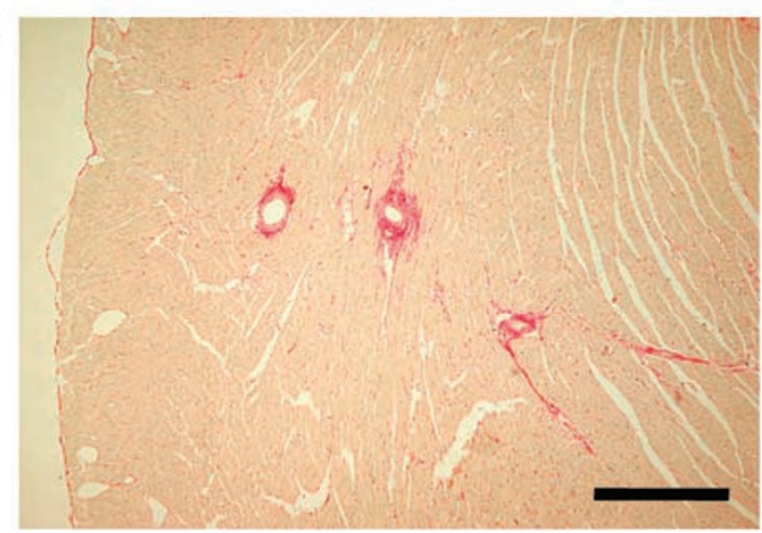

Figure 3 Accumulation of collagen. Photomicrographs of cardiac sections stained with Sirius red stain. (a) control group, (b) RHT group, (c) high-T group and (d) low-T group. Bar: $500 \mu \mathrm{m}$.
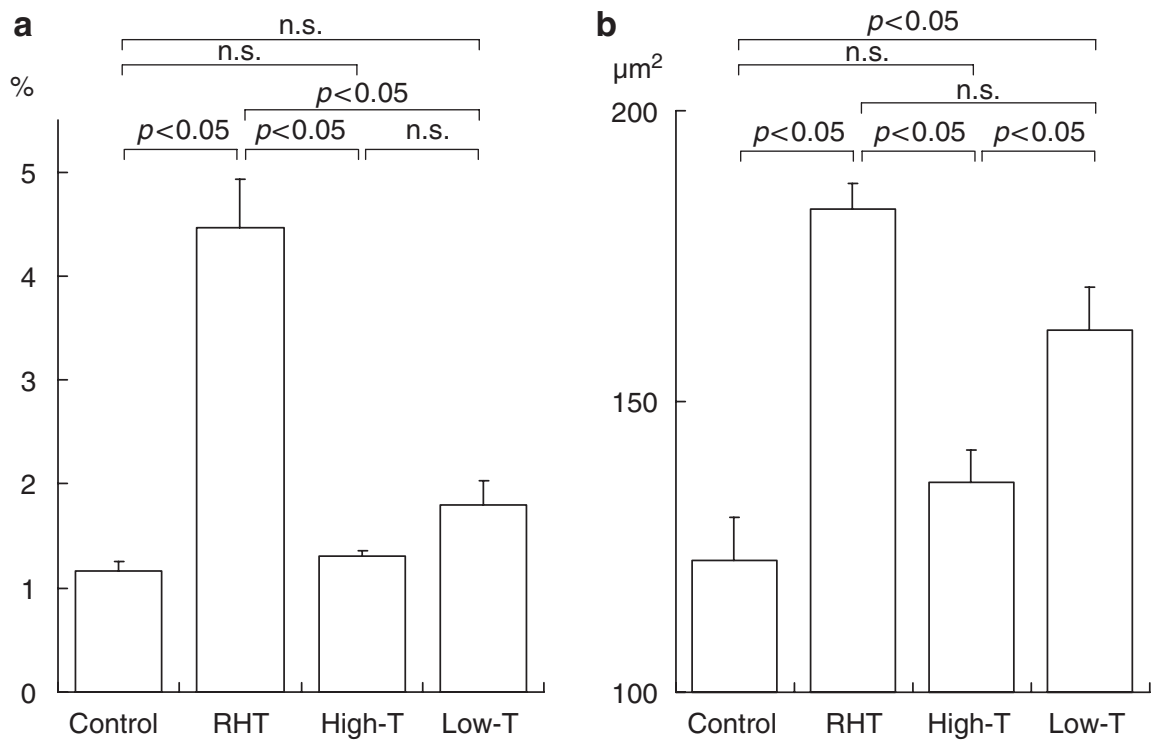

Figure 4 Differential effects of telmisartan on cardiac fibrosis (a) and CSA of myocytes (b). Values are the mean \pm s.e.m. $n=6-8$ for control, RHT, high-T and low-T rats. (a) Cardiac fibrosis (\%), ratio of cardiac fibrosis area to cross-sectional area of the heart; (b) CSA ( $\mu m^{2}$ ) of myocyte, 40-50 myocytes from each group were selected at random to determine the cell size; RHT, renovascular hypertensive rats without treatment; high-T, RHT rat treated with a high dose of telmisartan ( $5 \mathrm{mg}$ per kg per day for 4 weeks); low-T, RHT rat treated with a low dose of telmisartan ( $0.5 \mathrm{mg}$ per $\mathrm{kg}$ per day for 4 weeks).

PPAR $\gamma$-eNOS, oxidative stress and Rho-kinase pathway) in addition to its Ang II receptor blocking activity. ${ }^{17}$ Telmisartan also prevented high salt-induced interstitial and perivascular fibrosis in the cardiac ventricle as well as fibrosis in the aorta but only partially affected ventricle hypertrophy. Thus, AT1 receptor stimulation seems to play a critical role in hypertension and fibrosis but a lesser role in tissue 
hypertrophy. ${ }^{18}$ Furthermore, regarding the increase in collagen associated with fibrosis, the effect of telmisartan was shown in a report by Lijnen et al. ${ }^{19}$ The effects of Ang II on collagen secretion and production in adult rat cardiac fibroblasts were found to be mediated by the AT1 receptor because they were abolished by the specific AT1receptor antagonist telmisartan, but not by the specific AT2-receptor antagonist P-186. ${ }^{19}$ It is likely that the anti-fibrotic activity of telmisartan is derived from this multi-factorial mechanism. Thus, telmisartan, which inhibits the activation of the RA system, seems to strongly inhibit the progression of cardiac interstitial fibrosis.

A similar earlier study showed that low-dose candesartan does not prevent the occurrence of cardiac hypertrophy or cardiac fibrosis, even though the decrease in the blood pressure was almost the same as that in RHT rats treated with the angiotensin-converting enzyme inhibitor perindopril. ${ }^{10}$ However, cardiac fibrosis was strongly prevented by low and high doses of perindopril and high doses of candesartan. The difference between these results and those obtained with telmisartan may reside in the differences between the mechanisms of action of telmisartan and candesartan. Most Ang II related functions in the cardiovascular system are generally attributed to the stimulation of AT1 receptors. ${ }^{7}$ The action of Ang II may be inhibited by various ARBs, but the differences regarding the outcome of several kinds of ARB treatments do not seem to be related only to the binding affinity of ARBs to Ang II receptors.

Telmisartan is an AT1 receptor antagonist with a unique property; namely, it is also a partial agonist of peroxisome proliferator-activated receptor gamma (PPAR $\gamma)$. Earlier studies have shown that PPAR $\gamma$ activators suppress the expression of AT 1 receptors. ${ }^{20}$ Therefore, the dual inhibition of Ang II by telmisartan through the blockade and downregulation of AT1 receptors may lead to the complete inhibition of the RA system. This would explain the preventive effects of low doses of telmisartan on cardiac and perivascular fibrosis and interstitial collagen accumulation, despite the cardiac and vessel hypertrophy observed in the rats. Consequently, we suspect that the myocardial cellular hypertrophy observed in the untreated RHT rats may be mainly attributable to the action of AT1 receptors, whereas the differences in the cardioprotective actions of different types of ARBs are likely caused by other unknown mechanisms.

Another possibility is the involvement of aldosterone, which is known to induce cardiac hypertrophy and myocardial fibrosis directly ${ }^{21}$ and to play an important role in the proliferation of cardiac fibrosis in hypertensive animal models. ${ }^{22}$ Clinical and experimental studies have shown that treatment with an aldosterone blocker is effective against cardiac diseases. ${ }^{23,24}$ The aldosterone blocker spironolactone, either alone or in combination with valsartan, was shown to prevent the proliferation of interstitial and perivascular fibrosis in the hearts of RTH rats without causing a significant reduction in blood pressure. ${ }^{25}$ The secretion of aldosterone is mainly promoted by Ang II in the adrenocortex through AT1 receptors; therefore, ARBs should inhibit aldosterone secretion. In the above-mentioned study, treatment with low-dose valsartan did not prevent the proliferation of cardiac fibrosis, suggesting that valsartan may not have any significant effect against aldosterone-mediated cardiac remodeling; however, telmisartan did inhibit cardiac fibrosis in this study.

Few reports have discussed the changes in aldosterone levels caused by ARBs. It is conceivable that metabolites of Ang II, such as Ang III, might also stimulate the synthesis of aldosterone. ${ }^{26}$ The Ang II level may therefore increase as a result of stimulation through feedback pathways during ARB therapy; this would, in turn, increase the aldosterone level-in other words, an 'aldosterone breakthrough' would occur. Aldosterone breakthroughs have also been reported to occur during long-term ARB treatment in clinical and experimental studies. ${ }^{27,28}$

In this study, the serum aldosterone levels were measured in each group and both doses of telmisartan prevented an elevation in aldosterone in the RHT group. Telmisartan might strongly inhibit increases in serum aldosterone by blocking Ang II receptors in target organs. The present results show that telmisartan exerted a cardiovascular protective action and an antihypertensive effect; in addition, by strongly controlling the RA system through PPAR $\gamma$ activation, it also inhibited the increase in serum aldosterone.

Recent clinical studies have shown that slight changes in blood pressure can affect the mortality and morbidity of hypertensive patients receiving treatment with anti-hypertensive drugs. ${ }^{29}$ Therefore, the most important underlying factor for several cardiac abnormalities in hypertensive disease is the blood pressure level. The different blood pressure levels attained with the high dose and low dose of telmisartan in this study may have led to different cardiac abnormalities in our RHT rats. However, the level of blood pressure and the extent of cardiac or perivascular fibrosis were not significantly related in the telmisartan groups. These results suggest that the progression of cardiac hypertrophy in hypertension might be caused by different mechanisms from the progression of cardiac fibrosis, independent of the extent of blood pressure reduction.

\section{CONFLICT OF INTEREST}

The authors declare no conflict of interest.

\section{ACKNOWLEDGEMENTS}

We thank Nippon Boehringer Ingelheim Co., Ltd for providing the telmisartan bulk powder used in this study. This study was supported by the Jikei University Research Fund.

1 Gibbons GH, Dzau VJ. The emerging concept of vascular remodeling. N Engl J Med 1994; 330: 1431-1438.

2 Varagic J, Frohlich ED. Local cardiac renin-angiotensin system: hypertension and cardiac failure. J Mol Cell Cardiol 2002; 34: 1435-1442.

3 Dahlof B, Devereux RB, Kjeldsen SE, Julius S, Beevers G, de Faire U, Fyhrquist F, Ibsen $\mathrm{H}$, Kristiansson K, Lederballe-Pedersen O, Lindholm LH, Nieminen MS, Omvik P, Oparil $\mathrm{S}$, Wedel H. Cardiovascular morbidity and mortality in the Losartan intervention for endpoint reduction in hypertension study (LIFE): a randomised trial against atenolol. Lancet 2002; 359: 995-1003.

4 Pitt B, Poole-Wilson PA, Segal R, Martinez FA, Dickstein K, Camm AJ, Konstam MA, Riegger G, Klinger GH, Neaton J, Sharma D, Thiyagarajan B. Effect of losartan compared with captopril on mortality in patients with symptomatic heart failure: randomised trial-the Losartan Heart Failure Survival Study II ELITE. Lancet 2000; 355: 1582-1587.

5 Brown DW, Giles WH, Croft JB. Left ventricular hypertrophy as a predictor of coronary heart disease mortality and the effect of hypertension. Am Heart J 2000; 140: 848-856.

6 Robert V, Heymes C, Silvestre JS, Sabri A, Swynghedauw B, Delcayre C. Angiotensin AT1 receptor subtype as a cardiac target of aldosterone: role in aldosterone-salt-induced fibrosis. Hypertension 1999; 33: 981-986.

7 Unger T, Chung O, Csikos T, Culman J, Gallinat S, Gohlke P, Hohle S, Meffert S, Stoll M, Stroth U, Zhu YZ. Angiotensin receptors. J Hypertens Suppl 1996; 14: S95-S103.

8 Harada K, Komuro I, Shiojima I, Hayashi D, Kudoh S, Mizuno T, Kijima K, Matsubara H, Sugaya T, Murakami K, Yazaki Y. Pressure overload induces cardiac hypertrophy in angiotensin II type 1A receptor knockout mice. Circulation 1998; 97: 1952-1959.

9 Benson SC, Pershadsingh $\mathrm{HA}, \mathrm{Ho} \mathrm{Cl}$, Chittiboyina A, Desai P, Pravenec M, Qi N, Wang $\mathrm{J}$, Avery MA, Kurtz TW. Identification of telmisartan as a unique angiotensin II receptor antagonist with selective PPARgamma-modulating activity. Hypertension 2004; 43: 993-1002.

10 Nagai M, Horikoshi K, Izumi T, Seki S, Taniguchi M, Taniguchi I, Mochizuki S. Cardioprotective action of perindopril versus candesartan in renovascular hypertensive rats. Cardiovasc Drugs Ther 2004; 18: 353-362.

11 Obayashi M, Yano M, Kohno M, Kobayashi S, Tanigawa T, Hironaka K, Ryouke T, Matsuzaki M. Dose-dependent effect of ANG II-receptor antagonist on myocyte remodeling in rat cardiac hypertrophy. Am J Physiol 1997; 273: H1824-H1831. 
12 Zhuo JL, Mendelsohn FA, Ohishi M. Perindopril alters vascular angiotensin-converting enzyme, AT(1) receptor, and nitric oxide synthase expression in patients with coronary heart disease. Hypertension 2002; 39: 634-638.

13 Tanaka Y, Nagai M, Date T, Okada T, Abe Y, Seki S, Taniguchi M, Taniguchi I, Mochizuki $\mathrm{S}$. Effects of bradykinin on cardiovascular remodeling in renovascular hypertensive rats. Hypertens Res 2004; 27: 865-875.

14 Ito N, Isoyama S, Takahashi T, Takishima T. Coronary dilator reserve and morphological changes after relief of pressure-overload in rats. J Mol Cell Cardiol 1993; 25: 3-14.

15 O'Sullivan JB, Black MJ, Bertram JF, Bobik A. Cardiovascular hypertrophy in onekidney, one clip renal hypertensive rats: a role for angiotensin II? J Hypertens 1994; 12: $1163-1170$.

16 Matsubara LS, Matsubara BB, Okoshi MP, Franco M, Cicogna AC. Myocardial fibrosis rather than hypertrophy induces diastolic dysfunction in renovascular hypertensive rats. Can J Physiol Pharmacol 1997; 75: 1328-1334.

17 Kobayashi N, Ohno T, Yoshida K, Fukushima H, Mamada Y, Nomura M, Hirata H, Machida Y, Shinoda M, Suzuki N, Matsuoka H. Cardioprotective mechanism of telmisartan via PPAR-gamma-eNOS pathway in dahl salt-sensitive hypertensive rats. Am J Hypertens 2008; 21: 576-581.

18 Liang B, Leenen FH. Prevention of salt-induced hypertension and fibrosis by AT1receptor blockers in Dahl S rats. J Cardiovasc Pharmacol 2008; 51: 457-466.

19 Lijnen PJ, Petrov VV, Fagard RH. Angiotensin II-induced stimulation of collagen secretion and production in cardiac fibroblasts is mediated via angiotensin II subtype 1 receptors. J Renin Angiotensin Aldosterone Syst 2001; 2: 117-122.

20 Imayama I, Ichiki T, Inanaga K, Ohtsubo H, Fukuyama K, Ono H, Hashiguchi $Y$, Sunagawa K. Telmisartan downregulates angiotensin II type 1 receptor through activation of peroxisome proliferator-activated receptor gamma. Cardiovasc Res 2006; 72 : 184-190.

21 Robert V, Silvestre JS, Charlemagne D, Sabri A, Trouve P, Wassef M, Swynghedauw B, Delcayre C. Biological determinants of aldosterone-induced cardiac fibrosis in rats. Hypertension 1995; 26: 971-978.
22 Tanabe A, Naruse M, Hara Y, Sato A, Tsuchiya K, Nishikawa T, Imaki T, Takano K. Aldosterone antagonist facilitates the cardioprotective effects of angiotensin receptor blockers in hypertensive rats. J Hypertens 2004; 22: 1017-1023.

23 Slight SH, Joseph J, Ganjam VK, Weber KT. Extra-adrenal mineralocorticoids and cardiovascular tissue. J Mol Cell Cardiol 1999; 31: 1175-1184.

24 Pitt B, Zannad F, Remme WJ, Cody R, Castaigne A, Perez A, Palensky J, Wittes J. The effect of spironolactone on morbidity and mortality in patients with severe heart failure. Randomized Aldactone Evaluation Study Investigators. N Engl J Med 1999; 341: 709-717.

25 Okada T, Nagai M, Taniguchi I, Kuno M, Imamoto S, Seki S, Taniguchi M, Mochizuki S. Combined treatment with valsartan and spironolactone prevents cardiovascular remodeling in renovascular hypertensive rats. Int Heart J 2006; 47: 783-793.

26 Sasamura H, Suzuki H, Kato R, Saruta T. Effects of angiotensin II, ACTH, and $\mathrm{KCl}$ on the adrenal renin-angiotensin system in the rat. Acta Endocrinol (Copenh) 1990; 122: 369-373.

27 Naruse M, Tanabe A, Sato A, Takagi S, Tsuchiya K, Imaki T, Takano K. Aldosterone breakthrough during angiotensin II receptor antagonist therapy in stroke-prone spontaneously hypertensive rats. Hypertension 2002; 40: 28-33.

28 McKelvie RS, Yusuf S, Pericak D, Avezum A, Burns RJ, Probstfield J, Tsuyuki RT, White M, Rouleau J, Latini R, Maggioni A, Young J, Pogue J. Comparison of candesartan, enalapril, and their combination in congestive heart failure: randomized evaluation of strategies for left ventricular dysfunction (RESOLVD) pilot study. The RESOLVD Pilot Study Investigators. Circulation 1999; 100: 1056-1064.

29 ALLHAT Collaborative Research Group. Major outcomes in high-risk hypertensive patients randomized to angiotensin-converting enzyme inhibitor or calcium channel blocker vs diuretic: The Antihypertensive and Lipid-Lowering Treatment to Prevent Heart Attack Trial (ALLHAT). JAMA 2002; 288: 2981-2997. 